\title{
Directional Blasting Technology of Slit Charge for Geological Disposal of High-Level Radioactive Waste
}

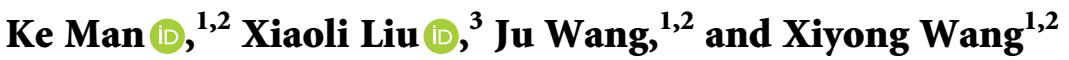 \\ ${ }^{1}$ Division of Environment Engineering, Beijing Research Institute of Uranium Geology, Beijing 100029, China \\ ${ }^{2}$ Key Laboratory of China National Nuclear Corporation on High Level Radioactive Waste Geological Disposal, \\ Beijing 100029, China \\ ${ }^{3}$ State Key Laboratory of Hydroscience and Hydraulic Engineering, Tsinghua University, Beijing 100084, China \\ Correspondence should be addressed to Ke Man; man_ke@sina.cn
}

Received 1 August 2018; Accepted 10 September 2018; Published 3 October 2018

Guest Editor: Zhanguo Ma

Copyright ( $2018 \mathrm{Ke}$ Man et al. This is an open access article distributed under the Creative Commons Attribution License, which permits unrestricted use, distribution, and reproduction in any medium, provided the original work is properly cited.

\begin{abstract}
Based on the slit charge technology, the blasting progress and the blasting theory have been studied in detail. Combined with the high-level radioactive waste geological disposal, in which the excavation damaged zone of the surrounding rock is required as small as possible, the testing of the Beishan exploration tunnel (BET) has been studied, and the blasting parameters have been designed using the slit charge technology. Theoretically, the rock failure criterion has been proposed, which adopted the dynamic mechanical parameters, such as the dynamic compress strength, dynamic tensile strength, dynamic modulus, dynamic passion ratio, dynamic fracture toughness, and dynamic stress intensity factor. Furthermore, the blasting test has been carried out under the same tunnel face with left and right sides simultaneously, and it can be found that the blasting effect with the slit charge technology is better than another side, which verified the useful and scientific meaning of this technology. It should be noticed that the blasting method includes numerous blasting parameters, which interact with each other. Those blasting parameters obtained just limited the slit charge, and the result and the theoretical knowledge could be applied to the blasting and excavation of the deep geoengineering and HLW geodisposal.
\end{abstract}

\section{Introduction}

High-level radioactive waste is an inevitable product of the nuclear industry. However, high-level radioactive waste has been accumulated by the fast development of nuclear power construction in China. According to National Nuclear Power Development and Long-term Plan (2005-2020) [1] approved by the State Council, it is expected that, by 2020, the installed capacity of nuclear power will reach 70 million kilowatts, the capacity of the installation is 30 million kilowatts, and there will be 13. 8200 tHM spent fuel produced by the whole life period of nuclear power that should be safely disposed, which becomes a major safety problem to be solved.

According to the strategy for the geological disposal of high-level radioactive waste, the construction of URL (Underground Research Laboratory) for the high-level radioactive waste is required during the 13th Five-Year Plan in
China, and the URL is a necessary verification facility for the construction of high-level radioactive waste geological disposal. As one of the largest projects, nuclear waste disposal has been raised to the national level. Therefore, the construction of the URL for high-level radioactive waste is imminent, and the demand is very urgent.

At present, the deep geological disposal is the universal acceptable solution to the disposal of high-level radioactive waste [2-5], that is, to bury the high radioactive waste in a geological body with a depth of about $500-1000 \mathrm{~m}$ from the surface. So that it is permanently isolated from the human living environment. Therefore, the deep geological disposal method will be adopted in China [6-8]. How to excavate the URL and the disposal repository and how to design the rock blasting implementation plan during the construction process are of vital significance to ensure the stability and safety of the repository. 
Drilling and blasting method or TBM mechanical excavation method is usually used for the chambers excavation of high-level radioactive waste disposal. No matter which excavation method is adopted, the rock breaking effect and the disturbance to the surrounding rock are two main considerable factors in the construction and monitoring progress, and these two factors restrict each other [7, 8]. Not only the over excavation of the surrounding rock is required but also the under excavation is demanded during the construction; that is, the positive energy should be promoted, and the negative energy should be limited, which correspond to a high excavation speed and a small rock damaged zone separately.

How to control the excavation concisely and induce the rock crack occurring, growing, penetrating, and generating a prefractured surface is a main question and key problem for the stability of rock engineering [9-15], such as the underground engineering, mine mining, tunnel construction, and railway application.

In 1950s, the smooth blasting method has been put forward in Sweden. Because the damage of surrounding rock can be effectively controlled by this method and it also can efficiently break rock, the smooth blasting technology has been popularized in a large amount and has been applied to the engineering. Especially, the design and selection of blasting parameters are very important. There are many scholars at home and abroad who have carried out a large number of analysis and research [16-22] based on different starting points of the blasting mechanism.

Among them, the blasting mechanism of the directional fracture technology using the slit charge is analyzed [23-28], and the differences and advantages between the directional fracture blasting of the slit charge and the cutting hole and the concentrated blasting are compared in detail. Furthermore, the blasting formula of the slit charge can be used to realize the directional fracture of the tunnel better. Meanwhile, coal mine and other engineering have been carried out, and a good blasting effect has been achieved. This paper tries to use the slit charge technology combined with the geological disposal of high-level radioactive waste, to carry out the directional blasting test of the slit charge and to compare and analyze the blasting effect, finally to give a guidance to the excavation of the subsequent disposal engineering.

\section{Engineering Background of BET}

As a technical research facility for the geological disposal of high-level radioactive waste in China, the BET (Beishan exploration tunnel) facility has carried out various construction skills related to the excavation engineering, such as the blasting test, rock deformation monitoring, EDZ monitoring, advanced detection, and grouting test. The main difference between BET project and the other underground projects is that it demands the EDZ value as small as possible. As the underground repository facilities need to be safe for thousands of years, it means that the nuclides must be ensured that they could not migrate from the surrounding rock to the nature.

In view of the actual working conditions of the BET facility, the blasting parameters of the slit charge used in the drilling and blasting test are designed, and the directional blasting test of the slit charge is emphasized. The cutting and slit charge blasting technology of the granite rock in this area is analyzed and discussed.

BET facility is located in Gobi, Gansu Province, about $80 \mathrm{~km}$ northeast of Yumen City. The main project of BET facilities includes the tunnel door, inclined shaft, alley, water storehouse, test chamber, shelter, ventilation hole, and the water supply, power supply, and ventilation system. The surrounding rock of the project is mainly granite, and its static compressive strength is $150 \mathrm{MPa}$, while the tensile strength is $13 \mathrm{MPa}$. The fracture (F18) moved toward $60^{\circ}$, which tended to be NW or SE, with a dip angle of $75 \sim 85^{\circ}$. The tectonic fracture zone is fragmented and fractured, especially in the center of the tectonic belt. The blasting parameters are quantified by theoretical calculation and semiempirical analysis, respectively. The longitudinal wave velocity of the rock is $3500 \mathrm{~m} / \mathrm{s}$. The emulsion explosive is used in the surrounding blasting holes to be cut into several segments on average, using air spacing with uncoupled charge.

The blasting excavation test and the other tests are carried out, as shown in Figure 1.

It is located in the monitoring chamber at the bottom site of the inclined shaft, which is close to the test chamber for drilling and blasting, and each blasting cycle footage is $2 \mathrm{~m}$.

A millisecond delay with a nonelectric detonator is used to detonate; the cutting holes adopt continuous coupling charge, the auxiliary holes and the bottom holes adopt continuous noncoupling charge, and the surrounding holes adopt the air interval with noncoupling charge to bind the interval of the explosive to the detonator and then attach the bamboo sheet to the bottom of the hole. The blockage length of the blasting hole is as follows: the surrounding hole, auxiliary hole is not less than $20 \mathrm{~cm}$, and the cutting hole is not less than $40 \mathrm{~cm}$.

At the same time, in order to ensure the blasting effect during construction, the quality of the drilling holes need to be controlled, so as to achieve a standard of parallelism, straightness, neatness, and accuracy.

Firstly, parallel means that the drilling holes are parallel to each other and parallel to the roadway heading direction. Secondly, straight means that the blasting hole must be perpendicular to the blasting face. Thirdly, neat means that the drilling holes are on the same bottom, which can guarantee the fracture of the tunnel at the same position. Fourthly, accurate means that the holes are drilled concisely, the hole arrangement is accurate, and the contour line cannot be deviated much.

The location of the drilling holes should be on the predesigned contour line of the roadway. The bottom of the hole should be controlled within $100 \mathrm{~mm}$ of the contour line, and the inclination angle should be controlled within $3^{\circ}$.

During the drilling implementation process, we can measure and record the hole parameters by means of the angle gauge, steel ruler, and straight stick to ensure the drilling quality.

\section{Rock Failure Mechanism of Directional Blasting Using Slit Charge}

The directional blasting technology of slit charge is mainly based on the principle of shaped charge blasting. The slit 


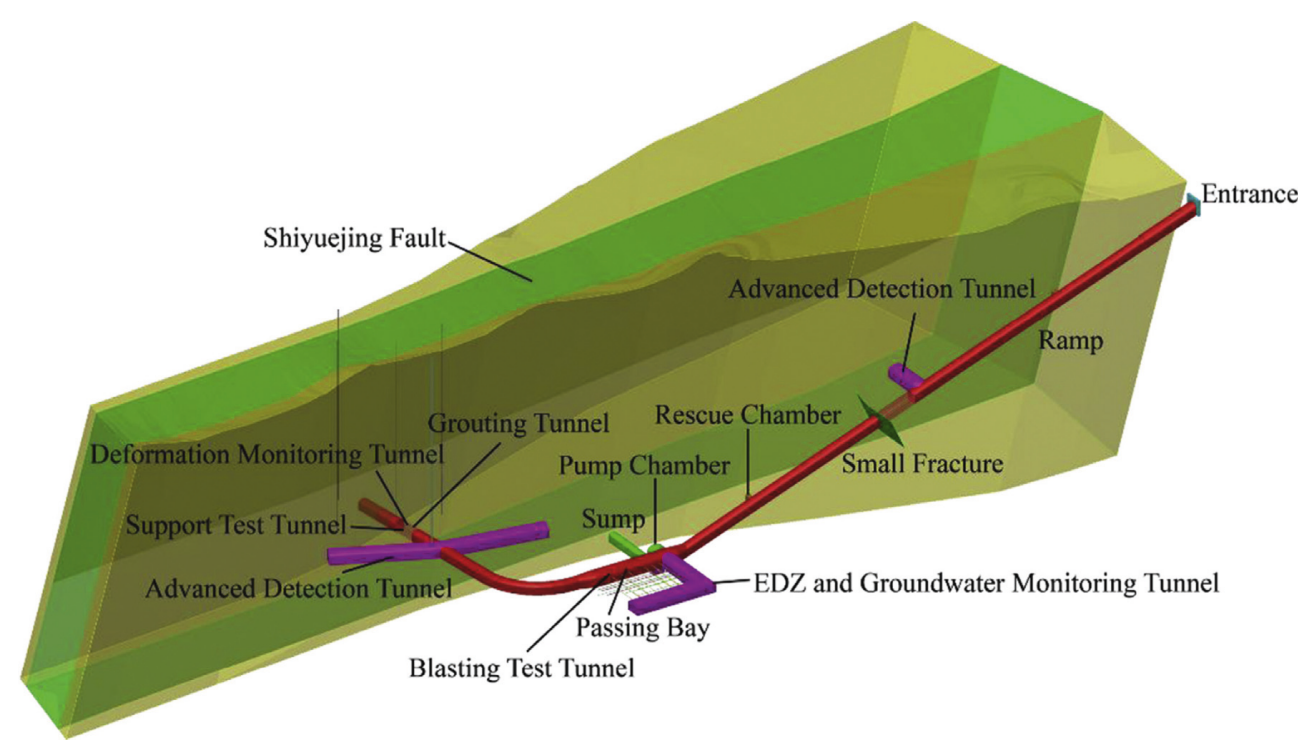

Figure 1: Site for the blasting test.

pipe can be made of different materials such as the PVC tube or copper tube, and its wave impedance is different from that of rock. The size of the slit pipe is determined by the diameter and length of ordinary rock emulsion explosive and the inside and outside diameters of the slit pipe. At the same time, the slit pipe with different cutting widths and different cutting angles can be machined.

As shown in Figure 2, the left side is the slit pipe, and its longitudinal section is along the diameter direction, and the right side is the detailed description of the slit pipe's cross section, where $A$ is the longitudinal side view of the slit pipe with a certain width of the cutting seam, and B is the cross section of the slit pipe, while 1 is the loading part, 2 is the air medium, 3 is the slit pipe, 4 is the hole wall, and 5 is the rock particle with a distance $R$ away from the center of the explosive bag. The distance $R$ can also be described by the axis angle $\theta$ and the distance from the hole wall $r . r_{1}$ is the radius of the explosive, $r_{2}$ is the radius of the slit pipe, and $b$ is the gap between slit pipe and borehole wall. Obviously, there exists a relationship between those parameters; that is $R=r+r_{2}+b$.

When the explosive is detonated, the explosion shock wave is generated instantaneously. The shock wave acts on the surface of the slit pipe. Between them, some of the shock waves acting on the cutting seam will continue to propagate along the slit, and some of the shock waves acting on the slit pipe's surface will produce the transmission and reflection waves, in which the impact of the transmissive wave entering the gap will be acted on the hole wall. And the reflected tension wave coupled with the shock wave inside the slit pipe, which is also mixed with exploding gas, has a certain period, resulting in the energy cumulative effect.

The impact wave at the cutting seam propagates directionally along the slit due to the energy cumulative effect, until it acts on the rock wall. Then, the rock is transmitted and broken. The subsequent exploding gas continues to expand and extend along the blasting induced

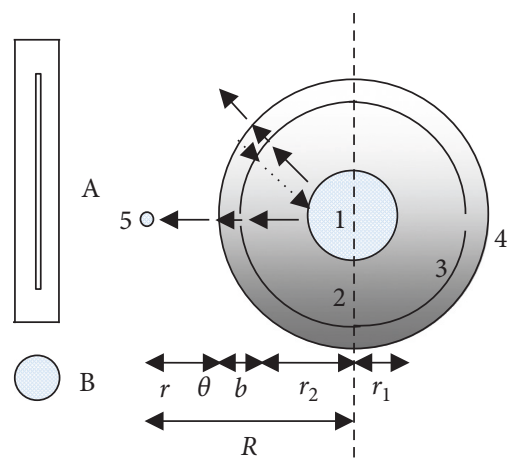

Figure 2: Schematic of the slot blasting principle.

crack until the rupture in the blasting area. Therefore, the energy cumulative effect and directional blasting of the explosive could be realized by the slit charge technology, and it also has a certain protective effect on the wall surface of the noncutting direction. Above all, it is of great significance to the rational use of explosives and the damage control of rock engineering.

From the point of the blasting mechanism, because of the existence of the slit seam, the stress condition between the slit seam holes is not the common effect of compression by the shock wave and the exploding gas, but the tensile stress forced on the rock, which changes the rock failure mechanism. Rock, as a quasibrittle material, it is known that its compressive strength is far greater than its tensile strength, and the difference is at least one order of magnitude. Usually, its compressive strength is several hundred $\mathrm{MPa}$, but its tensile strength is generally several $\mathrm{MPa}$. According to those factors, if we want to crush the rock efficiently, it needs to be stretched in the tensile stress state as more as possible.

No matter which testing methods are used, such as uniaxial compression, three axial compression, and direct or indirect tensile tests, from the mesoangle, the failure 
mechanism is analyzed either to be tensile failure or to be tensile-shear failure. Mainly, it is a pure compressive stress carried out on the rock by the shock wave and the stress wave under blasting. Only when the wave propagates to the free surface, the wave reflection occurs, and the tensile unloading wave is produced. Therefore, the rock is subjected to tensile stress, which is beneficial to the rock cracking. But the compression failure is produced on the rock wall very near the charge hole, and the rock wall is directly damaged into rock powder by the explosion wave.

Precisely, because of the existence of the slit charge blasting hole, the compression and tensile shock waves along the slit direction are more strongly influenced than that in the other directions. Especially, the crack surface which has been caused by the early shock wave has been largely impacted by the subsequent shock wave, causing the rock mass in the slit direction to be more easily unloaded, spalling and crushing. At the same time, explosive gas is more likely to expand along these cracks, and the role of explosive gas in the slit is more intense than that originated by ordinary cartridge. Definitely, because of the slit charge, the rock mass surrounding the cutting seam is much easier to produce tensile fracture and easier to be broken out.

Furthermore, the role of slit charge for the single blasting hole can be divided into the following aspects. Firstly, the cutting seam plays a good role in accumulating the explosive wave after blasting. Most of the explosive energy is propagated along the cutting seam to the rock wall of the blasting hole, and the tangential stress produced by the blasting causes the radial crack around the blasting hole, and the crack is extended forward by the subsequent explosive gas. Secondly, the slit pipe has a negligible effect on the explosive energy. Because of the slit pipe, explosive energy and detonating gas are limited to the slit pipe for a certain period, which is a little longer than that of the nonslit pipe.

Therefore, the energy will be released for a longer time, and the residence time of the explosive gas in the charge space is prolonged. Moreover, the slit pipe has a good guiding effect on blasting energy. Most of the energy is released along the slit direction, which is more fully blasted, and the deformation is much more than the direction vertical to the slit or other directions. Finally, the slit charge technology has a certain protective effect on the blasting hole wall. Due to the wave resistance difference between the slit pipe and the rock medium, in addition to the transmission wave of the slit pipe, the reflection wave will also occur, which could be limited in the slit pipe and wait for the energy to be released again. And the released energy is still more transmitted from the slit. During this process, the rock blasting hole which is not along the slit direction is protected.

As for the blasting engineering, the cutting seam package and the slit charge technology are used in the surrounding blasting hole, which can fully play the protective effect on the rock wall, and also lead to the directional and concentrated effects.

It should be noted that, due to the existence of the slit hole, a free surface is produced in the rock mass, and the stress concentration occurs. It means that the stress here is far greater than the stress in other places, and the rock between the slit holes is subjected to not only the impact pressure but also the tensile stress. Especially, the connected direction of the slit hole is the place where the maximum tensile stress is generated, and the rock failure caused by tensile stress is more likely to occur. In the case of simultaneous initiation of a double slit charge way, the stress wave is firstly propagated along the slit direction, resulting in the initial crack. Then, with the opposite propagation of the stress waves between the two holes, the peak stress of the blasting can reach a number of several GPa in the center. So, the initial crack can propagate through each other under such high stress.

At the same time, from the point of the superposition of the stress wave, the crack formation should be analyzed. It is found that the penetrating crack can be formed between the two holes through the reasonable design of the blasting hole diameter, the slit pipe diameter, the slit charge size, and so on.

To sum up, the slit hole can lead to the rock failure more easily along the line between the slit holes, and the slit charge plays a good guidance role in the failure process, which is more conducive to the performance of the explosive.

\section{Directional Blasting Technology Using Slit Charge}

Definitely, the characteristics of the high-level radioactive waste geological disposal demand a higher safety grade for the buried nuclear waste. Rock permeability increases by the formation of new cracks in the damaged area and the expansion of the original fissure in the rock. Therefore, the potential channel for the nuclide migration is provided. In addition, the mechanical properties of the rock and the operation period of the disposal repository are highly influenced by the excavation damage. No matter which excavation method is adopted, the rock breaking effect and the disturbance to the surrounding rock are two main considerable factors in the construction and monitoring progress, and these two factors restrict each other.

For the geological disposal of high-level radioactive waste, it is very important to recognize the relationship between the elastic modulus, deformation, permeability coefficient, heat conduction coefficient, and solute diffusion coefficient of the excavation zone.

At the same time, the blasting design and damage verification for rock mass are still a hot topic in blasting engineering. Especially for the geological disposal of highlevel radioactive waste, how to carry out the blasting design of engineering rock mass is a challenge.

The geological disposal facilities of high-level radioactive waste extend from the surface to a certain depth in the deep underground, which requires that the surrounding rock damage caused by the excavation is as small as possible because the fracture of the surrounding rock will continue to initiate, expand, or even interconnect in the rock mass, resulting in the loss of the disposed nuclear waste in a certain period of time, which is absolutely not allowed. No matter blasting or mechanical excavation method is used, the surrounding rock will be damaged, and this damage is unavoidable. 
Therefore, it is very important to adopt a suitable method to reduce the rock damage. Through the above description, it can be seen that accurate blasting could be achieved by the slit charge directional blasting technology, which can play the role of directional blasting, energy gathering blasting, and the protection of surrounding rock. And it can lead to a small damage range and can ensure the long-term safety of the geological disposal of high-level radioactive waste.

The essence of directional fracture blasting of the slit charge is that the cutting slit with different angles, shapes, and numbers on the certain density and strength explosive shell is formed. Then, the charge mode with a certain accumulation of explosive energy is generated between the slit charge and the blasting hole. The design blasting parameters and the failure criteria of directional blasting using the slit charge are discussed below.

4.1. Design of the Blasting Parameters. The hole spacing is quantified by the theoretical calculation and semiempirical analysis. The strength coefficient of the rock in the experimental tunnel is 8 , and the wave velocity is $3500 \mathrm{~m} / \mathrm{s}$. The emulsion explosive is used, and the air uncoupled charge way is adopted. Explosive density is $1000 \mathrm{~kg} / \mathrm{m}^{3}$, and the velocity of the explosive is $4000 \mathrm{~m} / \mathrm{s}$. The diameter of the explosive is $3.2 \times 10^{-2} \mathrm{~m}$, the diameter of the blasting hole is $4.2 \times 10^{-2} \mathrm{~m}$, and the length of the hole is $2.0 \mathrm{~m}$.

According to the blasting principle, the radial stress and tangential stress of rock mass at a distance $r$ away from the center of the borehole are, respectively,

$$
\begin{aligned}
& \sigma_{\mathrm{r}}=P_{2}\left(\frac{T_{b}}{T}\right)^{a}, \\
& \sigma_{\theta}=b \sigma_{\mathrm{r}},
\end{aligned}
$$

where $\sigma_{\mathrm{r}}$ is the radial stress; $\sigma_{\theta}$ is the shear stress; $b$ is the ratio of the tangential stress to the radial stress, and $b=\mu /(1-\mu) ; a$ is the attenuation index of the stress wave, and $a=2-b ; T_{b}$ is the radius of the blasting hole; $T$ is the radius of the explosive; and $P_{2}$ is the impact stress on the blasting hole wall surface.

The impact pressure on the hole wall as using the uncoupling charge is as follows:

$$
P_{2}=\frac{1}{8} \rho_{0} D^{2}\left(\frac{d_{\mathrm{c}}}{d_{\mathrm{b}}}\right)^{6} n,
$$

where $\rho_{0}$ is the explosives density; $D$ is the explosive velocity, while $d_{\mathrm{c}}$ and $d_{\mathrm{b}}$ are the diameter of the explosive and the blasting hole; and $n$ is the pressure increasing coefficient of the detonation impacting on the hole wall.

However, when the air uncoupled charge is adopted, the impact pressure on the hole wall is as follows:

$$
P_{2}=\frac{1}{8} \rho_{0} D^{2}\left(\frac{d_{\mathrm{c}}}{d_{\mathrm{b}}}\right)^{6}\left(\frac{L_{\mathrm{c}}}{L_{\mathrm{c}}+L_{\mathrm{a}}}\right) n,
$$

where $L_{\mathrm{a}}$ is the length of the air column interval and $L_{\mathrm{c}}$ is the length of the explosive charged.
4.2. Criterion of the Directional Blasting Technology. Under the action of tangential tensile stress, the criterion condition of breaking fracture is

$$
\sigma_{\theta} \geq S_{\mathrm{td}}
$$

where $S_{\mathrm{td}}$ is the dynamic tensile strength of the rock. Moreover, the relationship between tangential stress and radial stress is

$$
\begin{gathered}
\sigma_{\theta}=\frac{\mu \sigma_{\mathrm{r}}}{(1-\mu)}, \\
S_{\mathrm{td}}=C+\sigma_{\theta} \tan \varphi,
\end{gathered}
$$

where $C$ is the dynamic cohesion and $\varphi$ is the dynamic friction angle of rock.

According to Formulas (4)-(6), under the condition of the single hole, when the crack is formed by the tangential tensile stress, the radial stress $\sigma_{\mathrm{r}}$ should be satisfied:

$$
\sigma_{\mathrm{r}} \geq \frac{(1-\mu) S_{\mathrm{td}}}{\mu} \text {. }
$$

At the same time, at the crack tip under the blasting stress wave action, it is

$$
K_{\mathrm{I}}^{\mathrm{d}}=\sqrt{\pi r} P_{2} Y_{\min }^{*},
$$

where $K_{\mathrm{I}}^{\mathrm{d}}$ is the dynamic fracture toughness and $Y_{\min }^{*}$ is a dimensionless stress intensity factor at the crack tip, which reflects the size and shape of the crack, and it is an inherent index of the rock material.

Under the continuous action of the explosive stress wave, the crack continues to expand and should be satisfied as follows at the crack tip:

$$
K_{\text {Id }}>K_{\mathrm{I}}^{\mathrm{d}}
$$

where $K_{\text {Id }}$ is the dynamic stress intensity factor at the crack tip, which varies with the crack propagation.

It can be seen that Formula (7) is the criterion condition of initial crack formation during slit charge blasting, and Formula (9) is the criterion condition of crack propagation and extension under the blasting progress.

\section{Directional Blasting Experiment Using Slit Charge}

According to the actual engineering geology, the blasting test using the slit charge technology was carried out at the same free face with the left and right positions separately. Among them, the surrounding hole of the left side uses the ordinary charge structure, and the surrounding hole of the right side adopts a slit charge structure. Therefore, it can make a more accurate comparison and analysis for the slit charge technique. The blasting effect can be measured by parameters such as the over excavation amount and the half hole ratio after blasting. The specific test is described as follows.

5.1. Production of the Slit Pipe. The slit pipe is made of the PVC tube with an outer diameter of $32 \mathrm{~mm}$ and an inner 


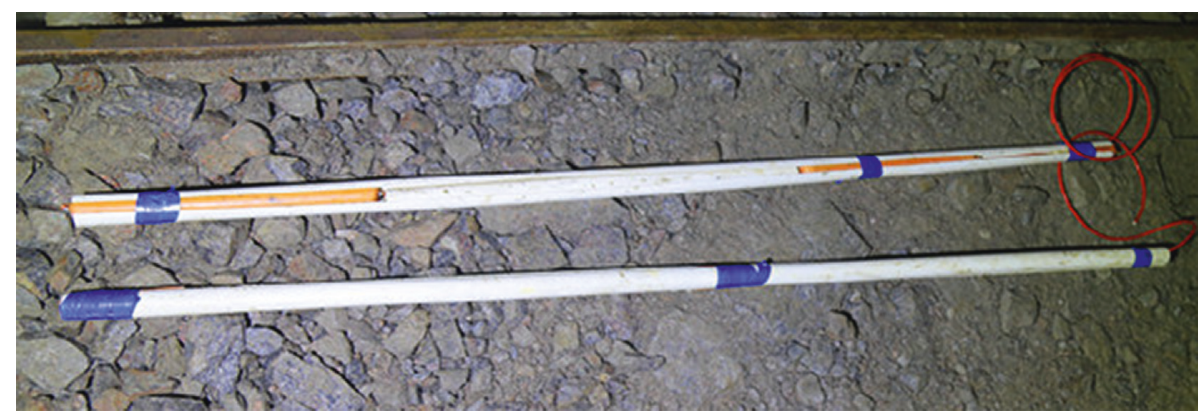

Figure 3: Slit pipe.

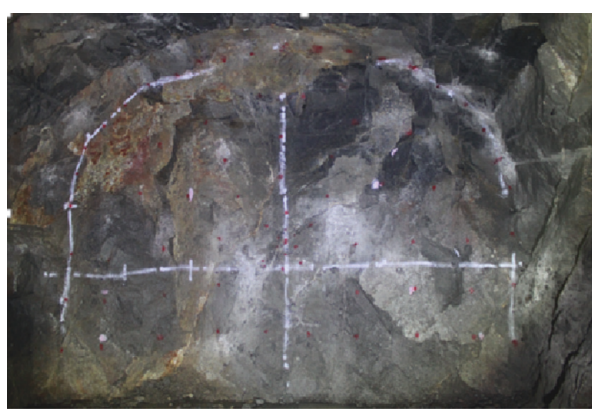

(a)

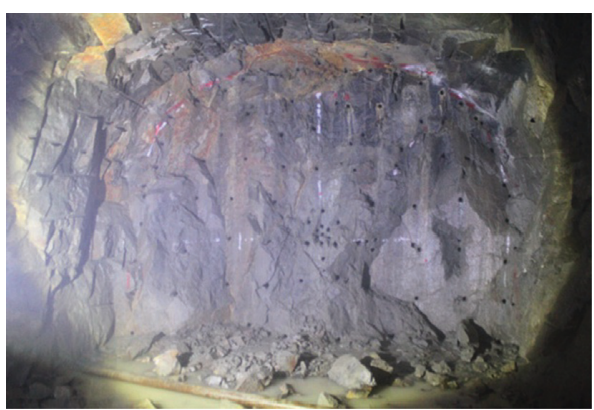

(b)

FIGURE 4: Borehole distribution.

diameter of $30 \mathrm{~mm}$. With an emulsion explosive inside, the diameter of the explosive is $32 \mathrm{~mm}$, and the slit width of the slit pipe is $2 \mathrm{~mm}$, as shown in Figure 3.

It must be noticed that in the process of charging, the direction of the slit must be consistent with the direction of the contour of the tunnel cross section. Otherwise, the explosive energy will burst more along the other directions but induce the tunnel forming worse.

It is a key point that must be paid attention before the preparation of the slit charge, and it is also the inherent attribute determined by the directional fracture blasting principle of the slit charge.

5.2. Arrangement of the Blasting Hole. The distances of the surrounding hole both in the left side and the right side were $300 \mathrm{~mm}$. As for the left side, the ordinary explosive charge was installed, with three intervals, and each length was $550 \mathrm{~mm}$. At the bottom of the hole, it was charged with 0.5 volume explosive, and the other 0.25 volumes were installed at each section. However, the surrounding hole in the right side was charged using the slit charge with the same installed way and explosive quantity.

The blasting cutting method is straight parallel cutting way. The layout of the blasting hole before and after drilling is shown in Figure 4.

5.3. Blasting Scheme. Based on the above theory of directional fracture technology of slit charge, the blasting scheme is designed. The blasting scheme for the slit charge is shown in Figure 5.

The blasting sequence is divided into 9 segments, which starts from the cutting hole, auxiliary hole, to the surrounding hole, and in the end to the bottom hole.

The length of blockage in the cutting hole is $600 \mathrm{~mm}$, and that in the other holes is $300 \mathrm{~mm}$.

The number of explosives and detonator segments in each hole is shown in Table 1 , and the section area is $12.15 \mathrm{~m}^{2}$, and the specific charge is $2.51 \mathrm{~kg} / \mathrm{m}^{3}$.

5.4. Blasting Effect. The designed footage driving cycle is 2 meters, while the penetration of blasting has reached $1.7 \mathrm{~m}$ in the left and $1.95 \mathrm{~m}$ in the right, which corresponds to the ordinary and slit charge separately. Meanwhile, the utilization ratio of blasting hole in the right is higher.

The right side using the slit charge has more than $90 \%$ of the half hole rate, and the blasting effect is smooth and even. However, the effect of the smooth blasting in the left side is not so good. As can be seen from Figure 6, the rock concave and convex exist a lot, and the half-hole ratio is low.

Image process of the profile after blasting and the ratio of over excavation or under excavation are calculated by the proportional image. It is found that over excavation quantity of the right side using the slit charge is small than that in the left side. And it shows a better blasting effect using the slit charge. Those phenomenon and descriptions illuminate that the surrounding holes using the slit charge could make the cross section contour of the tunnel better and smooth after blasting. 

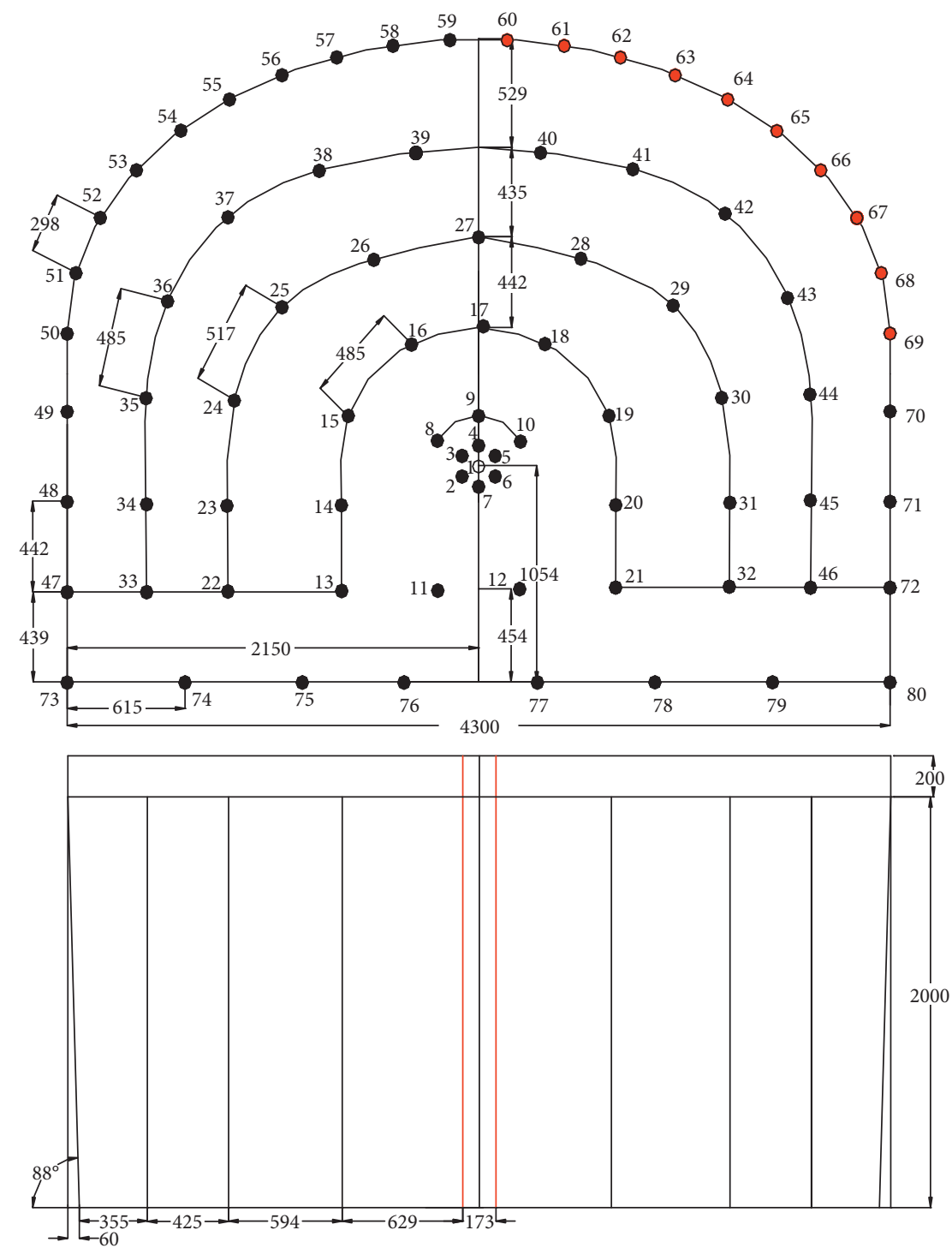

FIGURE 5: Blasting scheme of the slit charge technology.

TABLE 1: Blasting parameters table for the scheme.

\begin{tabular}{|c|c|c|c|c|c|}
\hline \multirow{2}{*}{ Hole name } & \multirow{2}{*}{ Hole number } & \multirow{2}{*}{ Number of holes } & \multicolumn{2}{|c|}{ Charge quantity } & \multirow{2}{*}{ Detonator order } \\
\hline & & & Each hole & Total weight $(\mathrm{kg})$ & \\
\hline Empty hole & 1 & 1 & 0 & 0.0 & \\
\hline Cutting hole & $2-7$ & 6 & 5 & 9.0 & 1 \\
\hline Auxiliary hole & $8-10$ & 3 & 5 & 4.5 & 3 \\
\hline Auxiliary hole & $11-12$ & 2 & 5 & 3.0 & 5 \\
\hline Auxiliary hole & $13-21$ & 9 & 3.5 & 9.45 & 7 \\
\hline Auxiliary hole & $22-32$ & 11 & 2.5 & 8.25 & 9 \\
\hline Auxiliary hole & $33-46$ & 14 & 2.5 & 10.5 & 11 \\
\hline Peripheral hole & $47-72$ & 26 & 1.5 & 9.0 & 15 \\
\hline Bottom hole & $74-79$ & 6 & 3 & 5.4 & 17 \\
\hline Bottom hole & 73,80 & 2 & 3 & 1.8 & 19 \\
\hline Total & & 80 & & 60.9 & \\
\hline
\end{tabular}

Furthermore, the variety between the charge composition and the charge structure is the main reason for the difference of the blasting effect.
According to the blasting principle described above, it can be found that, as the surrounding hole adopts the slit charge way, it can be easier to achieve directional fracture. 


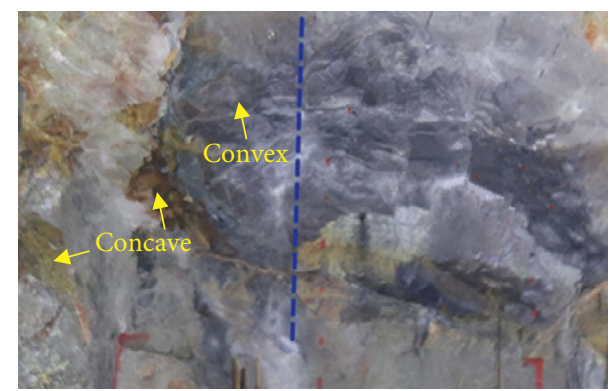

FIGURE 6: Blasting effect.

Rock around the surrounding hole is destroyed strictly along the cutting direction under blasting.

The explosive gas is triggered through the crack caused by the shock wave (just started in dozens of microseconds) and wedged into the internal microcracks in the surrounding rock. The energy accumulated in the crack tip more and more, and the stress concentration is more obvious, which leads to a greater dynamic stress intensity factor. It is much easier to extend and expand along the direction of the initial crack, which is more beneficial to the effect of the subsequent explosion stress wave, and it has played a good guidance role.

Correspondingly, there is less phenomenon of over excavation around the tunnel, and the smooth blasting effect is improved. It can be seen that the reasonable directional fracture technology using the slit charge is very important to smooth blasting.

\section{Conclusions}

(1) Based on the directional blasting technology of the slit charge, the explosive process and the failure principle are thoroughly explored. Combined with the blasting engineering for high-level radioactive waste geological disposal, the parameters of directional blasting in the BET exploration facility has been designed and discussed.

(2) The initiation and failure criteria of directional fracture blasting are analyzed deeply. The dynamic compressive strength, dynamic tensile strength, dynamic elasticity modulus, dynamic Poisson's ratio, dynamic fracture toughness, and dynamic stress intensity factor and other parameters are used to describe the criterion.

(3) Moreover, the blasting experiment of slit charge at different positions but the same tunnel face was carried out. It is found that the blasting effect is good at the right side using the slit charge, which proved that the blasting parameters calculated are reasonable. It is suitable to apply the directional fracture blasting technology using the slit charge to the highlevel radioactive waste geological disposal.

It should be pointed out that the drilling and blasting method covers many kinds of blasting parameters. The data obtained are only the preliminary exploration of the directional fracture blasting technology in the geological disposal of high-level radioactive waste. It can provide the experimental data and theoretical support for the blasting excavation of the high-level radioactive waste geological disposal, and it also has a certain guiding significance for the blasting excavation of the deep underground engineering.

\section{Data Availability}

The data used to support the findings of this study are available from the corresponding author upon request.

\section{Conflicts of Interest}

The authors declare that there are no conflicts of interest associated with this publication.

\section{Acknowledgments}

This work was supported by the National Natural Science Foundation of China (grant no. 41202207). The authors are most grateful to Professor Yue Z. W. for the valuable help with the tests.

\section{References}

[1] National Development and Reform Commission, Medium and Long-Term Plan for National Nuclear Power Development 2005-2020, National Development and Reform Commission, Beijing, China, 2007.

[2] Ministry of environmental protection of the People's Republic of China, Regulations on Radioactive Waste Management (GB14500-93), State Technical Supervision Bureau, Beijing, China, 1993.

[3] National Nuclear Safety Agency, Siting of Radioactive Waste Geological Disposal (HAD401/06), National Nuclear Safety Agency, Beijing, China, 1998.

[4] People's Republic of China, Law of Prevention and Control of Radioactive Pollution, Law Press, Beijing, China, 2003.

[5] National Defense Science, Technology and Industry Commission, Ministry of Science and Technology, and State Environmental Protection Administration, Guidelines for Research and Development Planning of Geological Disposal of High-level Radioactive Wastes, National Defense Science, Technology and Industry Commission, Beijing, China, 2006.

[6] Z. Pan and Q. Q. Hu, Strategic Study on Geological Disposal of High-Level Radioactive Waste, Atomic Energy Press, Beijing, China, 2009.

[7] Q. Q. Hu, "New progress in rock engineering technology in China," Chinese Engineering Science, vol. 12, no. 8, pp. 37-48, 2010.

[8] J. Wang, "On geological disposal of high level radioactive waste in China," Geology, vol. 7, pp. 33-35, 1998.

[9] Y. Yang, Technology and Safety of Blasting in Mine, Beijing: China Coal Industry Publishing House, Peking, China, 1991.

[10] W. Wang, Drilling and Blasting, Beijing:China Coal Industry Publishing House, Peking, China, 1984.

[11] Y. Gu, X. Li, Y. Du et al., "Reasonable smooth blasting factor used in tunnel," Journal of Chongqing University: Natural Science, vol. 28, no. 3, pp. 95-97, 2005.

[12] J. Dai and Y. Yang, "Analysis of controlled perimeter blasting in damaged rock," Journal of University of Mining and Technology, vol. 29, no. 5, pp. 496-499, 2000. 
[13] Y. Fu, X. Li, and L. Dong, "Analysis of smooth blasting parameters for tunnels in deep damaged rock mass," Rock and Soil Mechanics, vol. 31, no. 5, pp. 1420-1426, 2010.

[14] L. Huang, "Optimization and check of the main parameters in smooth blasting," Blasting, vol. 19, no. 3, pp. 20-21, 2002.

[15] J. Chen, X. Li, and J. Zhang, "Study on blasting parameters of protective layer excavation of rock bench based on blasting induced damage," Chinese Journal of Rock Mechanics and Engineering, vol. 35, no. 1, pp. 98-108, 2016.

[16] F. Dai, K. Xia, and L. Tang, "Rate dependence of the flexural tensile strength of Laurentian granite," International Journal of Rock Mechanics and Mining Sciences, vol. 47, no. 3,pp. 469475, 2009, In press.

[17] Q. Ma, "Definition of hole-space and burden in smooth blasting," Chinese Journal of Rock Mechanics and Engineering, vol. 16, no. 6, pp. 590-594, 1997.

[18] H. Hu, "The selection of smooth blasting parameters and quality control of tunnel in rocks," China Mining Magazine, vol. 16, no. 6, pp. 63-65, 2007.

[19] X. Wang, R. Shan, and B. Huang, "Application research on smooth blasting for cracked soft rock tunnelling," Blasting, vol. 25, no. 3, pp. 12-16, 2008.

[20] D. S. Chang, Y. Li, and C. Wu, "Exploration and practice of optimizing blasting parameters for improving driving efficiency of rock roadways," Coal Technology, vol. 26, no. 2, pp. 135-137, 2007.

[21] Y. Lu and D. Zhang, "Discussion on the parameters of surrounding eyes in smooth blasting construction," Coal Mine Blasting, vol. 3, no. 1, pp. 7-9, 2002.

[22] Y. Guo and D. L. Zhang, "Calculation and analysis of smooth blasting parameters for roadway tunneling in soft rock," Mine Pressure and Shift Management, vol. 5, no. 1, pp. 102-105, 2003.

[23] Y. Yang, R. Yang, Q. G. Chen et al., "Directional fracture controlled blasting mechanism and production test," Blasting, vol. 6, pp. 40-43, 1995.

[24] R. Yang, Q. Tong, and G. Yang, "Experimental study on cut blasting with slotted cartridge," Coal safety, vol. 1, pp. 11-14, 2010.

[25] Y. Tian, H. Tian, and R. Yang, "Study of the cut blasting with slotted cartridge on the rock tunnel," Mine Construction Technology, vol. 3, no. 6, pp. 10-12, 1997.

[26] Z. Yue, G. Yang, and P. Xu, "Analysis of empty hole effect in directional fracture controlled blasting," Explosion and Shock Waves, vol. 35, no. 3, pp. 304-311, 2015.

[27] R. Yang, X. Gao, J. Zuo et al., "Experimental study of blasting wave propagation mechanism on cutting seam cartridge," Journal of Coal Industry, vol. 35, no. 8, pp. 1434-1440, 2014.

[28] R. Yang, C. Ding, L. Yang, and Y. Wang, "Experimental study on controlled directional blasting on PMMA mediums with flaws," Chinese Journal of Rock Mechanics and Engineering, vol. 36, no. 3, pp. 690-696, 2017. 


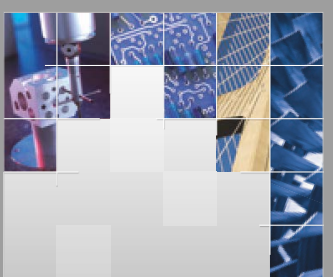

\section{Enfincering}
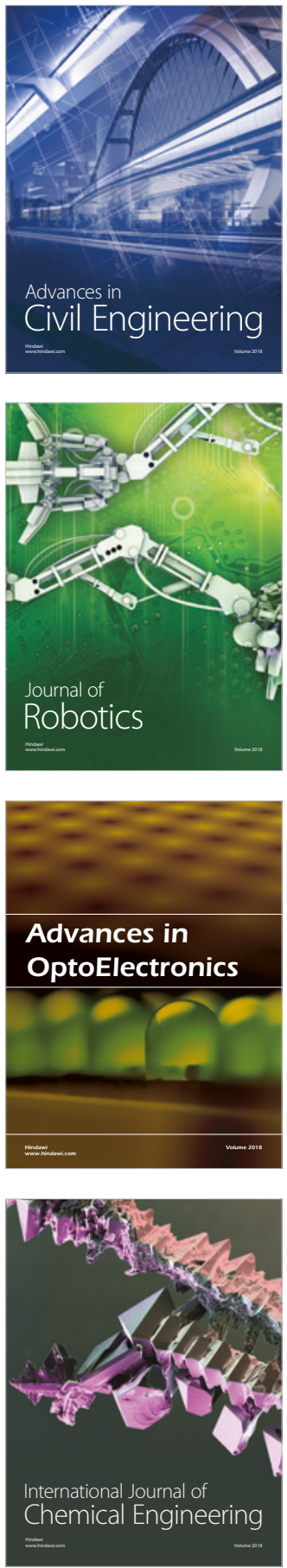

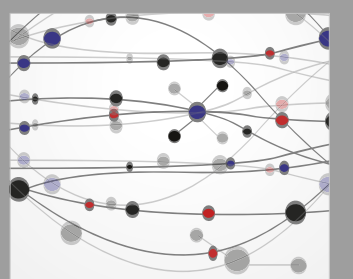

\section{Rotating \\ Machinery}

The Scientific World Journal

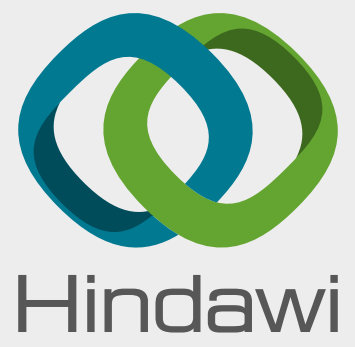

Submit your manuscripts at

www.hindawi.com
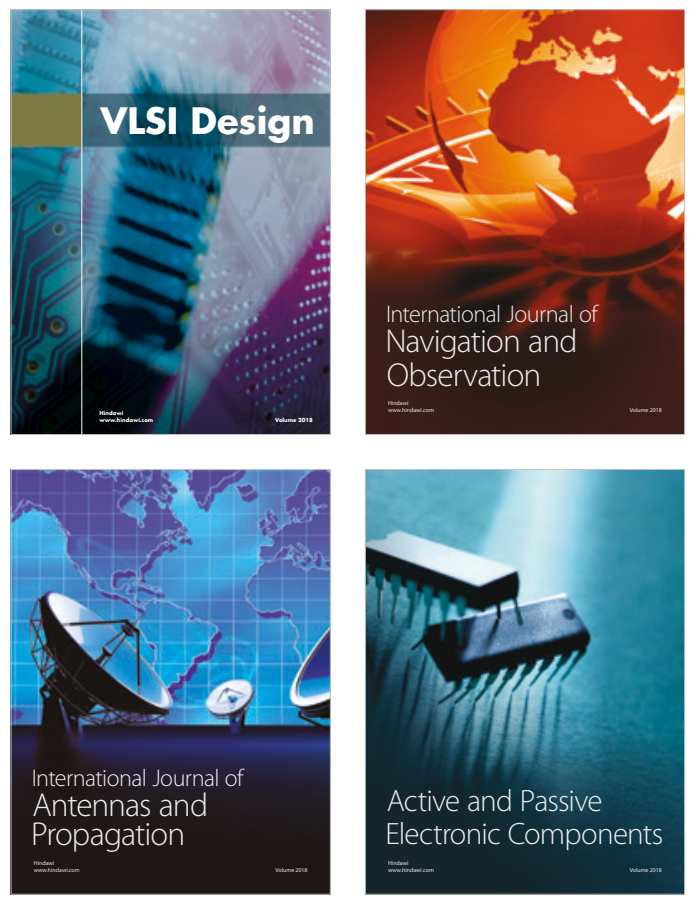
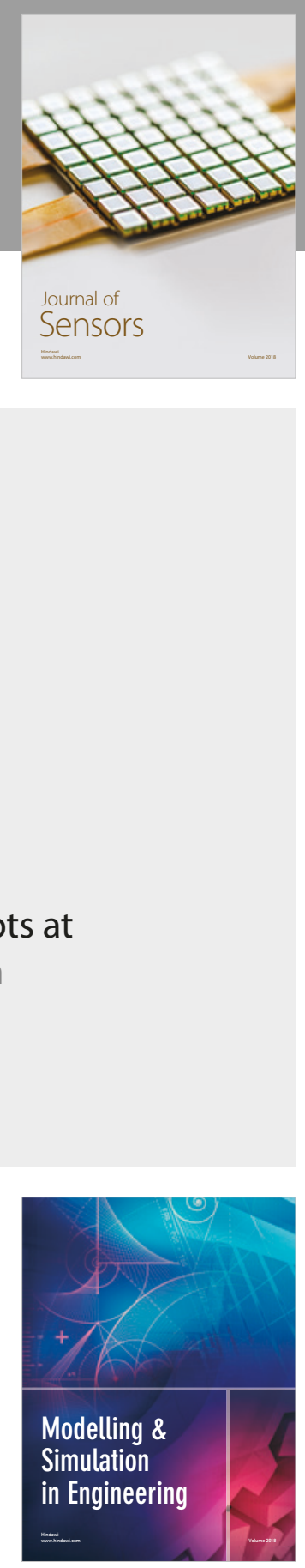

\section{Advances \\ Multimedia}
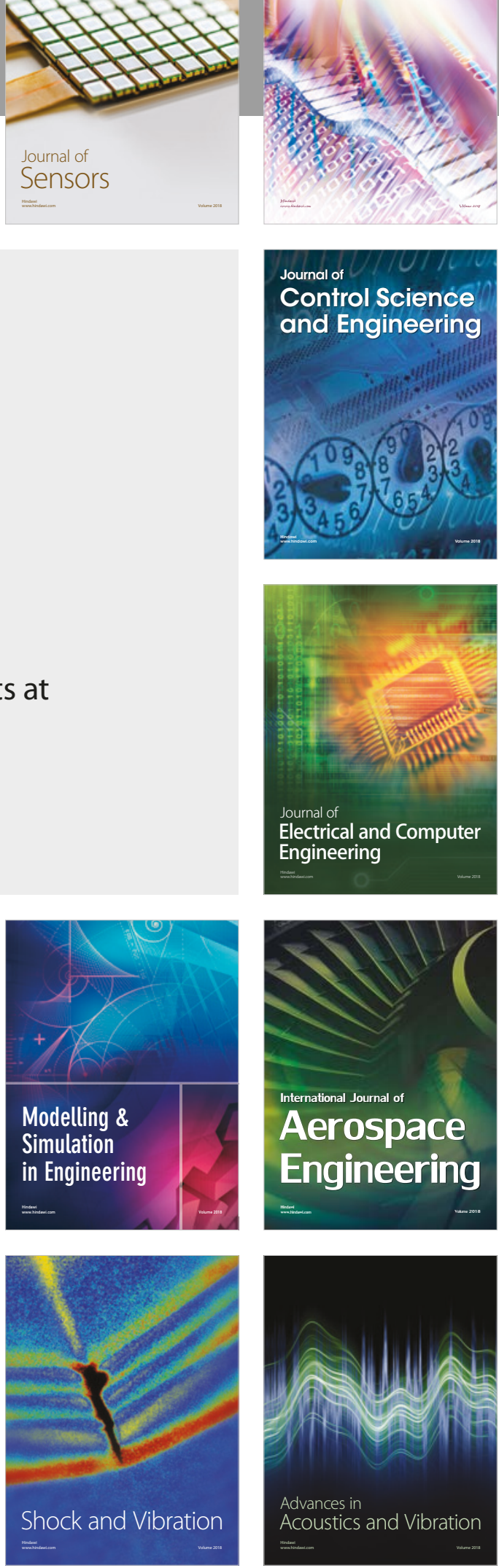